\title{
Systematic literature review on self-regulated learning in massive open online courses
}

\author{
Daeyeoul Lee, Sunnie Lee Watson, William R. Watson \\ Purdue University
}

\begin{abstract}
Despite arguments about the importance of self-regulated learning (SRL) in massive open online courses (MOOCs) (Terras \& Ramsay, 2015), understanding of the topic is limited. This study offers a systematic review of empirical research on SRL in MOOCs. It revealed that the body of literature on SRL in MOOCs has grown from 2014 to 2016. The content analysis findings show that SRL was a factor positively influencing learning in MOOCs. SRL strategies were identified, including motivational regulation strategies, specifically self-efficacy, task value, and goal setting. Particular cognitive regulation strategies were not identified, and goal setting was found as a metacognitive regulation strategy. Regarding behavioural and contextual regulation strategies, help seeking, time management, and effort regulation were identified. In addition, several MOOC designs and SRL interventions that consider unique characteristics of MOOCs were proposed to promote SRL. Implications of these findings and future research are discussed.
\end{abstract}

\section{Introduction}

A massive open online course (MOOC) generally refers to "a model for delivering learning content online to virtually any person-with no limit on attendance-who wants to take the course" (Educause Learning Initiative, 2011, ๆ 4). MOOCs have changed traditional online learning by putting hundreds of thousands of learners from different geographical locations into an online space where they study at their preferred pace and according to their own learning style (Johnson, Becker, Estrada, \& Freeman, 2014). Traditional online courses and MOOCs are distinguished by the fact that MOOCs are open to all applicants with freely accessible information and resources and do not typically require registration fees except for those learners seeking more formal certifications (Schulze, 2014). There is also a difference in goals and structures between regular online courses and MOOCs (Perna et al., 2014).

In MOOCs, "learners are expected to be autonomous and manage their own learning by making their own social and conceptual connections to suit their own needs” (Tschofen \& Mackness, 2012, p. 126). Glance, Forsey, and Riley (2013) and Barnes (2013) explained that most MOOCs usually include short lecture videos with embedded questions, auto-graded quizzes, peer reviewing or assessment, and online discussion forums. As MOOCs place "control of learning at the discretion of the learner” (Terras \& Ramsay, 2015, p. 1), it is essential to understand the learner behaviours required for autonomous learning in MOOCs (Terras \& Ramsay, 2015). While little has been discovered about learner behaviours in MOOCs, self-regulated learning (SRL) has recently gotten attention as a crucial factor related to learner behaviours in MOOCs (deWaard, 2011; Terras \& Ramsay, 2015).

SRL has been identified as one of the vital factors positively affecting students' success in traditional online learning environments (Cho \& Shen, 2013; Dabbagh \& Kitsantas, 2005). In addition, how to support online learners' SRL has been widely examined (e.g., Artino, 2008; Fisher \& Baird, 2005). Considering commonalities and differences between traditional online courses and MOOCs, there is a need for more empirical investigation of SRL in MOOCs. The findings of a recent analysis of research proposals submitted to the MOOC Research Initiative (MRI) show SRL and social learning is one of the five main topics for future MOOC research (Gasevic, Kovanovic, Joksimovic, \& Siemens, 2014). Although the analysis shed new light on the direction of future research on SRL in MOOCs, the results were limited to research proposals submitted to the MRI and did not cover completed empirical studies. The purpose of this study is to systematically analyse and report on the current state of research on SRL in MOOCs.

\section{Background literature}

SRL is generally defined as "an active, constructive process whereby learners set goals for their learning and then attempt to monitor, regulate and control their cognition, intentions and behavior, guided and constrained by their goals and the contextual features of the environment” (Pintrich, 2000, p. 453). While 
researchers have developed several SRL models with different constructs (e.g., Boekaerts, 1996; Butler \& Winne, 1995; Schunk, 1989 Zimmerman, 2000a), Pintrich (2000) developed a model classifying phases that other SRL models commonly shared (e.g., Zimmerman, 2000a) and areas for SRL. The model explains different aspects of SRL according to four phases: forethought, planning and activation; monitoring; control and reaction; and reflection.

The first phase of Pintrich's (2000) model consists of goal setting, planning, and activation of prior knowledge of the task, the context, and the self in connection to the task. The second phase involves monitoring processes. The third phase consists of controlling and regulating different parts of the task, the context, and the self. And the fourth phase consists of reaction and reflection on the task, the context, and the self. Areas of SRL consist of motivation/affect, cognition, behaviour, and context. SRL strategies identified in Pintrich, Smith, Garcia, and McKeachie's (1991) study are categorised in these areas. Motivational regulation includes intrinsic goal orientation, extrinsic goal orientation, control belief, selfefficacy, and text anxiety. Cognitive and metacognitive regulation consists of rehearsal, elaboration, organisation, critical thinking, and metacognitive self-regulation, which consists of monitoring, regulating, and planning, including goal setting and task analysis. Behavioural and contextual regulation are composed of time and study environment, effort regulation, peer learning, and help seeking.

SRL has been identified as one of the important factors for students' success in traditional online learning environments (Cho \& Shen, 2013). The findings of review research investigating empirical literature published from 1994 to 2006 indicated that self-efficacy had a positive correlation with the use of learning strategies, satisfaction with online courses, the likelihood of enrolling in future online courses, and academic performance (Artino, 2007). Broadbent and Poon's (2015) systematic review of research investigating SRL strategies related to academic achievement in online higher education settings published from 2004 to December 2014 found that time management, metacognition, effort regulation, and critical thinking had significant positive correlations with academic achievement in online higher education.

In terms of theoretical frameworks used in studies on SRL in online learning environments, the social cognitive model of SRL was particularly useful in analysing SRL and students' success in traditional online courses (Artino, 2007). According to social cognitive models of SRL (Schunk, 1989; Zimmerman, 2000a), learning occurs with reciprocal interaction between personal variables such as self-efficacy, behavioural variables such as use of learning strategies, and environmental variables. Using social cognitive models of SRL, studies on SRL in traditional online learning have focused on motivational components, especially self-efficacy and task value and the relationship between variables (Artino, 2007).

\section{Methods}

\section{Procedure}

This research was conducted based on the procedures of systematic reviews in social science, proposed by Petticrew and Roberts (2008). Systematic reviews are defined as literature reviews that stick closely to "a set of scientific methods that explicitly aim to limit systematic error (bias), mainly by attempting to identify, appraise and synthesize all relevant studies (of whatever design) in order to answer a particular question (or set of questions)” (Petticrew \& Roberts, 2008, p. 9). The study followed Petticrew and Roberts' (2008) seven stages of systematic review: defining the research questions or the hypothesis, determining the types of studies, conducting a comprehensive literature search, screening the search results, appraising the included studies, and synthesising the studies and assessing heterogeneity among the studies. The study also incorporated snowball methods (Greenhalgh \& Peacock, 2005), which were used after the fifth stage, and involved reviewing citations and references of the studies included in the systematic review.

For this study, first, research questions were clearly defined. The following research questions were drawn from the literature on SRL in traditional online learning environments:

(1) What is the status of studies on SRL in MOOCs published from 2008 to 2016?

(2) What effects of SRL on learning in MOOCs have been identified?

(3) What SRL strategies have been identified in the studies on SRL in MOOCs?

(4) What supports have been suggested to promote SRL in MOOCs? 
Second, criteria were established to determine the types of studies. Papers were limited to studies written in English and published in peer-reviewed journals in order to focus on quality, practicality and accessibility. The publication years were limited to between 2008 and 2016 based on the fact that academic papers on MOOCs first began to emerge in 2008 (Downes, 2008). In addition, inclusion and exclusion criteria were defined to screen the results of the search and select the most appropriate studies. Table 1 shows the inclusion and exclusion criteria that were set.

Table 1

Inclusion and exclusion criteria

\begin{tabular}{|c|c|}
\hline Inclusion criteria & Exclusion criteria \\
\hline Empirical studies investigating SRL in MOOC & Empirical studies examining SRL outside of \\
\hline learning environment & MOOC learning environment \\
\hline Empirical studies partially examining SRL in & Articles that present the same subcomponents of \\
\hline MOOC learning environment & SRL but were grounded in other theories \\
\hline $\begin{array}{l}\text { Empirical studies that use SRL as a theoretical } \\
\text { framework }\end{array}$ & Papers that provide only abstract \\
\hline Empirical studies that apply components of SRL & Papers that are presentation materials \\
\hline $\begin{array}{l}\text { Publications that represent subcomponents of } \\
\text { SRL based on the SRL theory }\end{array}$ & Papers that do not offer study results \\
\hline Articles that provide results & Duplicate report of the same study \\
\hline $\begin{array}{l}\text { Approved manuscripts which meet above } \\
\text { inclusion criteria }\end{array}$ & \\
\hline
\end{tabular}

\section{Databases and search terms}

After determining the types of studies to include or exclude, several databases and search terms were chosen to carry out the literature search. The search was modelled after a previous systematic review on SRL in online learning environments, which was conducted by Broadbent and Poon (2015). In terms of databases, the following databases were used for searching: Education Source, Education Full text, CINAHL, MEDLINE, ERIC, PsycINFO, PsycARTICLES, Web of Science, and Google Scholar. With respect to search terms, a total of 23 search terms were used to comprise the search strings with the following Boolean expression (A1 OR A2 OR A3... OR A23) AND (B1 OR B2). Search terms for SRL were partially adapted from Broadbent and Poon's (2015) study. The asterisk was used in the search terms to broaden a search by discovering words that begin with the same letters. Table 2 shows the terms that were used for searching.

Table 2

Search terms

\begin{tabular}{ll}
\hline A1. Self regulat* learning strategy* & $\begin{array}{c}\text { B1. Massive Open Online Course* } \\
\text { B2. Metacog* }\end{array}$ \\
A3. Learning strategy* & \\
A4. Self regulat* & \\
A5. Rehearsal & \\
A6. Elaboration & \\
A7. Critical thinking & \\
A8. Monitoring & \\
A9. Time management & \\
A10. Effort regulation & \\
A11. Peer learning & \\
A12. Help seeking & \\
A13. Goal setting & \\
A14. Environment structur* & \\
A15. Self efficacy & \\
A16. Task value & \\
A17. Planning & \\
A18. Intrinsic goal orientation & \\
A19. Extrinsic goal orientation & \\
A20. Control belief & \\
A21. Test anxiety
\end{tabular}




\section{Search results}

Papers on SRL in MOOCs were searched through a Midwestern university's library website and the Google Scholar website. In October 2016, the search of the selected databases was completed. The search query resulted in 1467 hits in Education Source, Education Full text, CINAHL, MEDLINE, ERIC, PsycINFO, and PsycARTICLES. It also resulted in 295 hits in Web of Science. In addition, there were 510 hits in Google Scholar according to relevance. In the first selection step, titles, keywords, and abstracts of searched articles were read and the inclusion criteria were applied to screen the inappropriate articles. Through this process, many articles were eliminated, and a total of 47 articles remained: 15 (Education Source, Education Full text, CINAHL, MEDLINE, ERIC, PsycINFO, and PsycARTICLES), 7 (Web of Science), 0 (Dissertations \& Theses), and 25 (Google Scholar). In the second selection step, titles and abstracts as well as contents of the 47 articles were read. Using the inclusion and exclusion criteria, 8 articles were excluded from the Education Source, Education Full text, CINAHL, MEDLINE, ERIC, PsycINFO, and PsycARTICLES. And an additional 19 articles were also excluded: 6 articles from Web of Science and 13 articles in Google Scholar. In the third step, the snowballing technique was performed on the remaining 20 articles. Reference lists of the 20 articles were scanned and citations to the papers were also tracked through the Web of Science database. This process resulted in an additional 3 articles. Two papers were excluded based on the exclusion criteria; one paper was presentation material, while another provided only the abstract. In the final step, the snowballing technique was implemented on the two papers, which gave rise to an additional paper. However, this paper was excluded as it did not provide study results. Finally, a total of 21 articles was selected as the most appropriate studies in this systematic review.

\section{Results and discussions}

Based on the research questions that were defined, the contents of the 21 articles were analysed. The results and discussions are provided below.

\section{RQ1: What is the status of studies on SRL in MOOCs published from 2008 to 2016 ?}

Twenty out of 21 studies on SRL in MOOCs were published from 2014 to 2016. One paper was an approved manuscript which would be published in 2017. Among the total of 21 studies, two papers were published in 2014 and 7 papers were published in 2015. In addition, 11 papers were published in 2016. These results indicate that the topic of SRL in MOOCs has increasingly received attention from researchers and educators, and the body of empirical research on SRL in MOOCs has been growing, particularly since 2014. These findings are consistent with previous findings that SRL is one of the main themes of future research on MOOCs (Gasevic et al., 2014).

\section{RQ 2: What effects of SRL on learning in MOOCs have been identified?}

Two studies show the effectiveness of SRL on MOOCs. In Magen-Nagar and Cohen's (2016) study, the results of the structural equation modelling path analysis show that learning strategy was a significant mediator for motivation and a sense of academic achievement in a MOOC for high-school students in flipped classroom settings. Kizilcec, Pérez-Sanagustín, and Maldonado (2016) found that goal setting and strategic planning were significant positive predictors of learners' goal achievement for three personal course goals: earning a course certificate, completing assessment, and watching lectures in the course. In addition, they discovered that learners who reported a high level of SRL skills in goal setting, strategic planning, self-evaluation, task strategies, and elaboration were apt to revisit course materials, especially in course assessment. Studies on SRL in regular online learning found that SRL has positive effects on academic achievements (Artino, 2007). On the other hand, findings in this review show that SRL positively affects a sense of academic achievement, as well as motivation and learner behaviours. In light of these findings, MOOC instructors and designers should recognise the importance of SRL in MOOCs and should be able to support learners' SRL in MOOCs.

\section{RQ 3: What SRL strategies have been identified in the studies on SRL in MOOCs?}

Motivational regulation strategies: Self-efficacy and task value

Self-efficacy is defined as one's own beliefs in the ability to compete academic tasks (Pintrich, 1999). Five studies reported findings about self-efficacy. Three out of the 5 studies indicated that MOOC learners have 
high self-efficacy. Littlejohn, Hood, Milligan, and Mustain (2016) found that participants who were working as data professionals both with overall high SRL levels and low SRL levels had high self-efficacy scores in the Self-Regulated Learning at Work Questionnaire (SRLWQ). According to Morales Chan, Hernandez Rizzardini, Barchino Plata, and Amelio Medina (2015), all participants recorded high selfefficacy scores in the Motivated Strategies for Learning Questionnaire (MSLQ) in their SRL profiles. The results of the interviews in Milligan and Littlejohn's (2016) study indicate that 28 out of 35 participants identified as health professionals mentioned their high self-efficacy.

Findings from two studies provide evidence that self-efficacy is highly connected to familiarity with the task (Zimmerman, 2000b). The results of the interviews in a study by Littlejohn et al. (2016) revealed that high self-efficacy scores particularly relate to previous exposure to MOOC content. Hood, Littlejohn, and Milligan (2015) also found that the most significant difference in self-efficacy scores in SRLWQ in a MOOC on teaching data science was between learners who were data professionals and those who were not. In addition, the results revealed that familiarity with MOOC platforms was also related to high levels of self-efficacy (Littlejohn et al., 2016). This is explained by the concept of online technologies selfefficacy, which has been actively examined in traditional online learning (Artino, 2007). Learners who feel comfortable with MOOCs do not need to spend much time figuring out how to watch lecture videos, use discussion boards, and assess peers' performances and feel confident in their ability to complete tasks in MOOCs.

In addition, self-efficacy for English was identified as a new form of self-efficacy. Liang-Yi (2015) found that there was a positive correlation between non-English learners' self-efficacy for English and cognitive learning strategies and motivation strategies. In traditional online SRL studies, many researchers have explored how the subcomponents of SRL relate to each other as well as how SRL relates to academic achievements as reviewed in Artino (2007). However, little has been uncovered about self-efficacy for English and SRL in traditional online learning environments. Considering that most MOOCs are offered in English and people around the world take them (Daniel, Cano, \& Cervera, 2015), non-native English learners' self-efficacy for English could be one of the factors influencing learner behaviours in MOOCs. Therefore, the findings of Liang-Yi's (2015) study suggest that MOOC practitioners could consider selfefficacy for English as one of the unique characteristics of MOOC learners when they design a MOOC offered in English.

Task value refers to beliefs about the importance of the task and interest in the task (Pintrich, 1999). Findings from two studies demonstrated task value. According to Morales Chan et al. (2015), the highest mean values of MSLQ were shown in task value, and there was a significant positive correlation between the task value, intrinsic goal orientation, and self-efficacy. In addition, qualitative findings specifically showed what values learners who have high levels of SRL place on tasks. The results of interviews in a study by Littlejohn et al. (2016) indicated that learners who worked as data professionals with high SRL levels placed greater value on the acquisition of skills and content knowledge in a MOOC than those with low SRL levels. Learners with high SRL levels were also more likely to connect the value of learning in a MOOC with professional contexts and roles because they perceived the usefulness of what they learned in the MOOC for their workplace. In light of these findings, it behooves MOOC instructors and designers to provide opportunities for learners to recognise the usefulness of MOOC content or how the content aligns with their interests so that learners recognise the task value.

In summary, studies on SRL in MOOC settings have investigated the extent to which learners have selfefficacy, task value, the values they place on MOOC learning, and what is related to their self-efficacy. On the other hand, studies on SRL in traditional online settings have focused on the relationships between variables such as self-efficacy, task value, and academic performances (Artino, 2007). This difference may be attributed to different theoretical frameworks. While social cognitive models of SRL have been mainly used in regular online courses, SRL models based on varied constructs (e.g., Pintrich, 2000; Zimmerman, 2000a) have been adopted in the selected studies. In addition, as SRL in the workplace has been increasingly emphasised (Margaryan, Littlejohn, \& Milligan, 2013), professionals’ motivational regulation strategies in MOOC environments have actively been investigated. MOOC practitioners and researchers could promote the forethought and planning phase for MOOC learning by considering self-efficacy and task value. 
Cognitive and metacognitive regulation strategies: Goal setting

Cognitive regulation strategies consisting of rehearsal, elaboration, organisation, and critical thinking were not identified in the selected studies. However, task strategy, which is regarded as a cognitive regulation strategy, was examined in three studies (Hood et al., 2015; Littlejohn et al., 2016; Milligan \& Littlejohn, 2016). Littlejohn et al. (2016) discovered through interviews that high SRL level learners who identified as data professionals were apt to have more flexibility in their approach to learning and determined their learning paths by themselves. In contrast, low SRL level learners were more apt to be linear and followed a structured approach to learning. Hood et al. (2015) found that learners who identified as data professionals had higher scores in task strategy in SRLWQ than those who took a MOOC for higher education qualifications. In Milligan and Littlejohn's (2016) study, 20 out of 35 participants stated in interviews that they took notes while taking a MOOC. However, there were differences between learners in terms of approach to learning. In terms of modification of learning approach, 20 out of 35 stated that they did not change their approach to the course because of their familiarity with the content and previous experiences with taking MOOCs. On the other hand, 15 out of 35 participants responded that they had changed their approach to learning while taking a MOOC.

Goal setting refers to setting task-specific goals that can provide guidance for cognition and metacognition (Pintrich et al., 1991). Five studies reported findings about goal setting. Findings of two studies showed that there are significant differences in the types of goals set. A study by Littlejohn et al. (2016) revealed that 12 out of 16 data professionals with high SRL levels mentioned in interviews that their goals focused on improving skills and knowledge in data science, which were tied to their workplace. In contrast, 7 out of 16 data professionals with low SRL levels tended to have goals related to extrinsic motivation, including certifications. In Milligan and Littlejohn's (2016) study, 28 out of 35 health professionals taking a MOOC responded that they set specific goals for a MOOC. The results of interviews revealed that the type of goals significantly varied, including extrinsic outcomes and specific goals related to course content or intrinsic benefits of learning to their career, current role or personal satisfaction. Another two studies showed that goal setting positively affected MOOC learning. The results of Jo, Tomar, Ferschke, Rose, and Gasevic's (2016) study revealed that learners following appropriate goal setters participated longer in a MOOC, actively engaged in hands-on learning activities, and tended to review previous course materials more. Kizilcec, Pérez-Sanagustín, and Maldonado (2017) found that goal setting and strategic planning predicted learners' goal achievement for personal course goals. The results of a study by Onah and Sinclair (2016) indicated that 27 undergraduate students taking a blended MOOC had mean scores of 3.6 in the Online Self-regulated Learning Questionnaire (OSLQ) developed by Barnard, Lan, To, Paton, and Lai (2009). Based on findings about goal setting, it is recommended that MOOC instructors and designers provide activities where learners set their own goals for MOOCs even if the individuals' goals vary considerably.

In summary, cognitive regulation strategies were not identified and goal setting was identified as a metacognitive regulation strategy. These do not align with findings of a review study on SRL in regular online settings, which showed that rehearsal, elaboration, and organisation, critical thinking, metacognition were actively examined to identify if they are related to academic achievements (Broadbent \& Poon, 2015). This inconsistency is explained by different conceptualisations of SRL. The selected three studies used Zimmerman's (2000a) model of SRL, which includes task strategy as a subprocess. However, findings identified in this review suggest that MOOC instructors or designers should also provide support for cognitive and metacognitive regulation processes based on the fact that MOOC learners used task strategies such as changing their approach to learning, taking notes, and setting goals.

Behavioural and contextual regulation strategies: Help seeking, time management, and effort regulation Help seeking involves seeking help from others (Pintrich et al., 1991). Findings of a study showed that there were differences between health professionals taking a MOOC in using the discussion forum (Milligan \& Littlejohn, 2016). For example, 17 out of 35 stated in interviews that they actively participated in the discussion forum in a MOOC. While 12 out of 17 viewed the discussion forum as a positive experience, five out of 17 were less positive. Findings from another study indicated that 27 undergraduate students taking a blended MOOC recorded mean scores of 3.25 in the OSLQ (Onah \& Sinclair, 2016). Considering MOOC learners should actively make connections with others, online discussion forums or social networking services could be vital sources of help seeking behaviours.

Time management refers to "scheduling, planning, and managing one's study time" (Pintrich et al., 1991, p. 25). Three studies showed that time management is a vital factor influencing MOOC learning. Survey 
results in Nawrot and Doucet's (2014) research showed that poor time management was the main cause of dropping out of a MOOC. In addition, the results of a study by Onah and Sinclair (2016) revealed that 27 undergraduate students taking a blended MOOC had low-level of time management scores in the OSLQ, showing mean scores of 2.95. These results are supported by several MOOC study findings that issues with time were one of the reasons for disengaging from MOOCs (Kizilcec \& Halawa, 2015). However, traditional online course findings showed that students who completed traditional online courses differed significantly from dropout students with respect to academic locus of control and metacognitive selfregulation (Lee, Choi, \& Kim, 2012). These differences in dropout reasons might be explained by the more autonomous structures of MOOCs or personal reasons such as workplace workload and requirements, which could lead to poor time management. In addition, in a study by Kizilcec et al. (2016), a survey of successful MOOC learners revealed that time management was considered as one of the most important SRL strategies for succeeding in MOOCs. This finding is supported by the results of a review study on SRL in online higher education settings showing that time management was positively related to academic performances (Broadbent \& Poon, 2015). Based on these findings, MOOC designers and practitioners should examine how to effectively support time management in a broad range of MOOC learners.

Effort regulation refers to controlling one's own effort and attention (Pintrich et al., 1991). The results of a survey in a study by Kizilcec et al. (2016) showed that effort regulation was the most important SRL strategy recommended by successful MOOC learners. While conclusions cannot be drawn from this single study, effort regulation strategy could be important in MOOC learning in light of previous findings that effort regulation strategy was positively correlated with improvement of academic achievement in regular online learning settings (Broadbent \& Poon, 2015). Learners are likely to complete a course and succeed in MOOCs if they are able to persist when they face distractions such as other websites while watching lecture videos and undertaking uninteresting tasks.

\section{New type of SRL behaviours emerging from MOOC data}

Findings from two studies showed that a new type of SRL behaviours which has not been identified in existing SRL models (e.g., Pintrich, 2000, Zimmerman, 2000a) emerged from MOOC data. In Diana, Eagle, Stamper, and Koedinger's (2016) study, results showed that attempting activities during video playback and re-reading page views were predictive of final exam performance. Campbell, Gibbs, Najafi, and Severinski (2014) found that learners used lecture videos and discussion forums as resources for SRL strategies while repeatedly attempting to take quizzes from clickstream MOOC data. Little has been uncovered about these new types of SRL behaviours in regular online settings. It could be attributed to the unique structures of MOOCs. As most MOOCs are designed with short lecture videos that include embedded questions, auto-graded quizzes and online discussion forums, behaviours related to them could be a new indication of how learners regulate their MOOC learning.

\section{RQ 4: What supports have been suggested to promote SRL in MOOCs?}

\section{SRL interventions}

SRL interventions were identified in four studies. Two interventions were software programs: a Learning Tracker prototype widget designed with features that allow MOOC learners to compare their behaviours with successful MOOC learners' behaviours (Davis, Chen, Jivet, Hauff, \& Houben, 2016), and ProSOLO software, which provides tracking of students' learning processes and course competencies (Dawson, Joksimović, Kovanović, Gašević, \& Siemens, 2015). One intervention consisted of prompts of study tips on recommended SRL strategies in MOOCs (Kizilcec et al., 2016). Another intervention was a discussion of SRL strategies in a face-to-face MOOC study group (Chen \& Chen, 2015). In addition, there were two types of interventions: retrieval practice cues embedded in a video lecture and a study planning module consisting of questions, examples, and reflection prompts (Davis, Chen, van der Zee, Hauff, \& Houben, 2016).

Among these SRL interventions, only the Learning Tracker prototype widget significantly increased students' success in terms of the final grade and engagement in the dimension of timeliness of the quiz answers (Davis, Chen, Jivet, et al., 2016). Learning Tracker is a dashboard, the main features of which are providing feedback and promoting metacognition through data visualisations of learners' own behaviours and successful learners' behaviours. On the other hand, four studies did not find any positive effects from SRL interventions. In a study by Kizilcec et al. (2016), there was no statistically significant difference in course outcomes and persistence between groups who were presented with study tips on SRL strategies 
employed by successful MOOC learners and those who were not. Dawson et al. (2015) revealed that the number of completed competencies in a MOOC was low in the ProSOLO software, which was developed based on the principles of SRL. Davis, Chen, van der Zee, et al. (2016) found that there were no statistically significant differences in weekly quiz grades and final grades between learners who got retrieval practice cues embedded in a video lecture in a MOOC and those who did not. In addition, there were no statistically significant differences in final grades, course persistence, and engagement between MOOC learners who were exposed to a module about study planning and those who were not (Davis, Chen, van der Zee, et al., 2016). Chen and Chen (2015) did not investigate the effectiveness of a discussion of SRL in a MOOC study group.

In traditional online courses, training and prompting have been mainly identified as effective interventions to support students' SRL for academic performances (Rowe \& Rafferty, 2013). In addition, web-based pedagogical tools and Web 2.0 tools have been used in online courses to promote SRL (e.g., Dabbagh \& Kitsantas, 2005; Kitsantas \& Dabbagh, 2011). On the other hand, researchers have tried to design SRL interventions such as a dashboard or platform that could be embedded in MOOCs. In light of these findings, MOOC researchers could design and develop unique software programs which fit in with MOOC platforms and provide personalised support for SRL. In addition, successful MOOC learners' SRL behaviours have been used as an indication of desired learner behaviours in MOOCs. These findings suggest that MOOC designers could consider the desired SRL behaviours which are applicable to most MOOC learners and how to promote their metacognition.

MOOC design

Five studies proposed different MOOC designs to promote SRL in MOOCs. Park, Cha, and Lee (2016) developed design guidelines for learning analytics to promote learners' SRL in MOOCs, as shown in Table 3.

Table 3

Design guidelines of learning analytics to promote SRL in MOOCs

\begin{tabular}{ll}
\hline Dimensions of SRL strategies & $\begin{array}{l}\text { Final design guidelines for facilitating SRL in MOOC } \\
\text { environments }\end{array}$ \\
\hline 1. Self-evaluation & 1.1. Content analysis of learners' reflection \\
& $\begin{array}{l}\text { 1.2. Learning history compared to others (achievements, progress, } \\
\text { activities, e-portfolio, etc.) }\end{array}$ \\
& 2.1. Learners' preferred contents types (video clips, texts, images, \\
2. Organising and & 2.2. Student's participant activity records to upload and author \\
transforming & contents \\
& 3.1. Setting learning objectives and plans for effective time \\
3. Goal setting and planning & management \\
& 3.2. Monitoring learners' plans \\
& 4.1 Records of students’ learning activities such as note-taking, \\
4. Keeping records and & searching, downloading, and printing \\
monitoring & 5.1 Details about participation in the exercise, discussion, \\
5. Rehearing and memorising & homework, etc. \\
6. Reviewing records & 6.1 Quantitative and qualitative analysis of learning exercise such as \\
& quiz, discussions and exams for reviewing \\
7. Seeking information & 7.1. References and links referred by learners and others \\
8. Seeking social assistance & 8.1. Q\&A to overcome problems or solve the problems \\
9. Self-consequences & 9.1. History of certificates or credits with invested time and earned \\
& achievement scores \\
10. Structuring personalised & 9.2. Enrolled and completed rates of courses monthly or annually \\
10.1. Recommending courses for each learners' level or interest
\end{tabular}
learning environments

10.2. Feedback on learning success and failure appropriate for individual learning

Note. Adapted from Park et al., 2016. 
Milligan and Griffin (2016) derived four MOOC design principles from progression of developmental continuum of crowd-sourced learning (C-SL) capability, which refers to the capability to create higher order learning. Among them, the second and fourth design principles address how to design a MOOC to promote SRL, as shown in Table 4.

Table 4

Design principles to promote SRL in a MOOC

Design principle 2: Scaffold activities to generate and support self-regulation, crowd-sourced learning

- $\quad$ Redesigned automated assessments as extension activities, exploring application and synthesis rather than recall and understanding of concepts covered in video materials.

- Doubled the number of automated quizzes and quiz questions, to cover most aspects of the course, allowing recursiveness, focus, and critical consumption.

- Targeted new quiz exercises to areas of confusion identified in first running

- Trimmed videos to reduce viewing time overall to encourage time commitment to production and engagement rather than consumption.

- Designed quiz exercises to clarity for participants the professional standards inherent in the major assignment, providing practice on using the rubrics provided for peer- and self-assessment.

Design principle 4: Support participants' metacognition of how to learn in a MOOC

- Messaged through weekly emails about purposes of forums, encouraging dialogues and reciprocity, risk-taking and perspective taking, and production.

- $\quad$ Provided a resource site that included description of expert behaviour and self-assessment tools

Note. Adapted from Milligan \& Griffin, 2016.

García Espinosa, Tenorio Sepúlveda, and Ramírez Montoya (2015) proposed a template design for MOOCs focusing on self-motivation and self-regulation to increase persistence and active participation of less motivated-students in a MOOC. Table 5 shows examples of a MOOC design template focusing on SRL.

Table 5

Template design of MOOC focusing on self-regulation and self-motivation

\begin{tabular}{|c|c|c|}
\hline Type of activity & Activity detail & OER support activities \\
\hline $\begin{array}{l}\text { Recognize low self-regulated or } \\
\text { self-motivated students }\end{array}$ & $\begin{array}{l}\text { Describe and justify the } \\
\text { procedure to identify such } \\
\text { students. }\end{array}$ & Survey, etc. \\
\hline Self-regulation promotion & $\begin{array}{l}\text { Generalized or voluntary call to } \\
\text { identify low self-regulated } \\
\text { students to perform activities } \\
\text { such as reducing distractions, } \\
\text { improving organization, } \\
\text { distinguishing important } \\
\text { information, looking for } \\
\text { assistance, etc. Offer at least } \\
\text { seven activities. }\end{array}$ & $\begin{array}{l}\text { Corrective activity, monitoring, } \\
\text { etc. }\end{array}$ \\
\hline
\end{tabular}

Note. Adapted from García Espinosa et al., 2015.

Nawrot and Doucet (2014) proposed MOOC system features as a solution to address time management, which, as Table 6 shows, was identified as a main cause of dropping out from a MOOC. 
Table 6

Proposed MOOC system features to support time management

\begin{tabular}{ll}
\hline Phases & System features \\
\hline Planning & 1) Tasks and activities identification \\
& MOOC platforms should offer the possibility to specify the tasks \\
& needed to accomplish the goals (specifically courses to take and \\
external resources to check) & 2) Time allocation \\
& MOOC platform should also provide support for predictive time \\
& allocation. \\
& 3) Scheduling features \\
: MOOC platform should assist their users in scheduling. & \\
MOOC platforms should send reminders, solve potential conflicts \\
and visualize progress. \\
MOOC platforms should provide them with reports on their progress \\
on each course and offer an overall progress report.
\end{tabular}

Note. Adapted from Nawrot \& Doucet, 2015.

Littlejohn and Milligan (2015) proposed two sets of design tools that can guide instructors and instructional designers in designing MOOCs to support professional learners' SRL: MOOC-SRL patterns and MOOC Design Team Questionnaire.

First, SRL patterns were designed based on the results of a survey and interview. They were presented in five categories: adaptable course goals/objectives, reflect on both theory and practice, capitalize on diversity, break down the barriers, and productive MOOCs. First, adaptable course goal/objectives explains that instead of setting rigid course objectives, it is recommended that instructors enable MOOC learners to set their own goals, which increases motivation and academic outcomes. Second, reflect on both theory and practice allows learners to connect what they learned in a MOOC with their professional work. Third, capitalise on diversity explains that MOOCs designers can allows learners to interact with others and build community unity by changing the challenges resulting from MOOC learners' diverse backgrounds and characteristics into benefits. Fourth, in the break down the barriers category, MOOC designers can encourage learners to bring their professional networks into courses, which can break down the barriers between work and learning. Finally, productive MOOCs explains that designers can provide authentic tasks to make MOOC learning more valuable to learners.

The MOOC Design Team Questionnaire was developed to help platform developers, course design teams, and instructors and course teaching assistants to design MOOCs that better support MOOC learners' SRL. It consisted of five broad categories: pedagogy overall, SRL overall, forethought phase, performance, and self-reflection.

In summary, each study designed a MOOC with a different focus. Perhaps the different theoretical frameworks of SRL such as Zimmerman and Pons' (1986) model and Zimmerman's (2000a) model lead to different forms of design guidelines or principles. As conceptualisations of SRL are diverse, MOOC designers could consider and select an appropriate framework of SRL when designing a MOOC. In addition, designing activities to promote SRL as well as aspects of technology such as lecture videos and automated-assessment could be a possible factor that MOOC designers or instructors could consider when designing MOOCs. While research on designing regular online courses has mainly focused on the integration of Web-based social media technologies with course design (e.g., Fisher \& Baird, 2005) or practical guidelines for instructors (Artino, 2008), specific design guidelines or templates have been proposed in selected studies. Findings identified in this review provide new insights on how to design MOOCs to support the SRL of a broad range of MOOC learners.

\section{Conclusion}

This systematic review describes the current state of research on SRL in MOOCs. This study showed that research on SRL in MOOCs has increasingly grown, as evidenced by the fact that articles from 2008 to 2016 were reviewed, but no relevant articles were identified until 2014. However, since 2014, 20 studies 
on SRL in MOOC have been published and an approved manuscript to be published in 2017 was identified. The findings of the present review confirmed the importance of SRL in MOOCs. It was revealed that SRL positively affected MOOC learning and learners used SRL strategies in MOOCs. Self-efficacy, task value, and goal setting have been examined as motivational regulation strategies. Particular cognitive regulation strategies were not identified and goal setting was identified as metacognitive regulation strategy in selected studies. Help seeking, time management, and effort regulation were identified as behavioural regulation strategies. Findings of SRL in MOOCs tend to be different from those of SRL in traditional online learning with respect to SRL strategy. This is attributed to different frameworks of SRL and the unique characteristics of MOOCs. In addition, it was found that diverse interventions such as dashboard and platform, and design guidelines or principles were suggested. Findings of this review could offer potential new insights and directions for future research on MOOCs. In addition, this study could provide MOOC practitioners with information about MOOC learner behaviours related to SRL and the importance of supporting SRL in MOOCs.

There are limitations when considering the implications of this study. As the search period for identifying potential articles concluded at a certain date, any articles published after that point would not be identified in this review. In addition, the scope of this review is limited to comparisons between empirical studies on SRL in traditional online courses and MOOCs. SRL strategies which were not grounded in Pintrich's (2000) model of SRL were not analysed. Based on the findings of this review, directions for future research are provided. First, researchers should investigate SRL in MOOC environments in an ongoing basis to contribute to the growing body of literature. In addition, they should investigate other SRL strategies that were not reviewed in this study, relationships between SRL strategies, and other aspects of SRL such as emotion regulation by using different models of SRL. Another recommendation is to further examine indications of new types of SRL behaviours from other MOOC data. Researchers should also examine the effectiveness of MOOC designs that were proposed in the selected studies. Finally, SRL of different professionals such as teachers in different contexts should be explored.

\section{References}

Artino, A. R. (2007). Self-regulated learning in online education: A review of the empirical literature. International Journal of Instructional Technology and Distance Learning, 4(6), 3-18. Retrieved from http://itdl.org/Journal/Jun_07/article01.htm

Artino, A. R. (2008). Promoting academic motivation and self-regulation: Practical guidelines for online instructors. TechTrends, 52(3), 37-45. http://dx.doi.org/10.1007/s11528-008-0153-X

Barnard, L., Lan, W. Y., To, Y. M., Paton, V. O., \& Lai, S. L. (2009). Measuring self-regulation in online and blended learning environments. The Internet and Higher Education, 12(1), 1-6. http://dx.doi.org/10.1016/j.iheduc.2008.10.005

Barnes, C. (2013). MOOCs: The challenges for academic librarians. Australian Academic and Research Libraries, 44(3), 163-175. http://dx.doi.org/10.1080/00048623.2013.821048

Boekaerts, M. (1996). Self-regulated learning at the junction of cognition and motivation. European Psychologist, 1(2), 100-112. http://dx.doi.org/10.1027/1016-9040.1.2.100

Broadbent, J., \& Poon, W. L. (2015). Self-regulated learning strategies \& academic achievement in online higher education learning environments: A systematic review. The Internet and Higher Education, 27, 1-13. http://dx.doi.org/10.1016/j.iheduc.2015.04.007

Butler, D. L., \& Winne, P. H. (1995). Feedback and self-regulated learning: A theoretical synthesis. Review of Educational Research, 65(3), 245-281. http://dx.doi.org/10.3102/00346543065003245

Campbell, J., Gibbs, A., Najafi, H., \& Severinski, C. (2014). A comparison of learner intent and behaviour in live and archived MOOCs. International Review of Research in Open and Distance Learning, 15(5), 235-262. Retrieved from http://www.irrodl.org/index.php/irrodl/article/view/1854/3097

Chen, Y. H., \& Chen, P. J. (2015). MOOC study group: Facilitation strategies, influential factors, and student perceived gains. Computers \& Education, 86, 55-70. http://dx.doi.org/10.1016/j.compedu.2015.03.008

Cho, M., \& Shen, D. (2013). Self-regulation in online learning. Distance Education, 34(3), 290-301. http://dx.doi.org/10.1080/01587919.2013.835770

Dabbagh, N., \& Kitsantas, A. (2005). Using web-based pedagogical tools as scaffolds for self-regulated learning. Instructional Science, 33(5-6), 513-540. http://dx.doi.org/10.1007/s11251-005-1278-3 
Daniel, J., Cano, E. V., \& Cervera, M. G. (2015). The future of MOOCs: Adaptive learning or business model? International Journal of Educational Technology in Higher Education, 12(1), 64-73. http://dx.doi.org/10.7238/rusc.v12i1.2475

Davis, D. J., Chen, G., Jivet, I., Hauff, C., \& Houben, G. (2016). Encouraging metacognition and selfregulation in MOOCs through increased learner feedback. CEUR Workshop Proceedings, 1596, 1722. Retrieved from http://ceur-ws.org/Vol-1596/paper3.pdf

Davis D., Chen G., van der Zee T., Hauff C., \& Houben G. J. (2016). Retrieval practice and study planning in MOOCs: Exploring classroom-based self-regulated learning strategies at scale. In K. Verbert, M. Sharples, \& T. Klobučar (Eds.), Adaptive and adaptable learning (pp. 57-71). Cham: Springer. http://dx.doi.org/10.1007/978-3-319-45153-4_5

Dawson, S., Joksimović, S., Kovanović, V., Gašević, D., \& Siemens, G. (2015, July). Recognising learner autonomy: Lessons and reflections from a joint x/c MOOC. In T. Thomas, E. Levin, P. Dawson, K. Fraser, \& R. Hadgraft (Eds.), Research and development in higher education: Learning for Life and Work in a Complex World (Vol. 38, pp. 117-129). Milperra: Higher Education Research and Development Society of Australasia.

deWaard, I. (2011, July 25). Explore a new learning frontier: MOOCs. Learning Solutions Magazine. Retrieved from https://www.learningsolutionsmag.com/articles/721/explore-a-new-learning-frontier$\underline{\text { moocs }}$

Diana, N., Eagle, M., Stamper, J., \& Koedinger, K. R. (2016, June). Extracting measures of active learning and student self-regulated learning strategies from MOOC data. In T. Barnes, M. Chi, \& M. Feng (Eds.), Proceedings of the 9th International Conference on Educational Data Mining (pp. 583584). Raleigh, NC: International Educational Data Mining Society.

Downes, S. (2008). Places to go: Connectivism \& connective knowledge. Innovate: Journal of Online Education, 5(1), 6. Retrieved from http://nsuworks.nova.edu/innovate/vol5/iss1/6/

Educause Learning Initiative. (2011). 7 things you should know about MOOCs. Educause Learning Initiative. Retrieved from https://library.educause.edu/ /media/files/library/2011/11/eli7078-pdf.pdf

Fisher, M., \& Baird, D. E. (2005). Online learning design that fosters student support, self-regulation, and retention. Campus-Wide Information Systems, 22(2), 88-107.

http://dx.doi.org/10.1108/10650740510587100

García Espinosa, B. J., Tenorio Sepúlveda, G. C., \& Ramírez Montoya, M. S. (2015). Self-motivation challenges for student involvement in the Open Educational Movement with MOOC. Revista De Universidad Y Sociedad Del Conocimiento, 12(1), 91-103. http://dx.doi.org/10.7238/rusc.v12i1.2185

Gasevic, D., Kovanovic, V., Joksimovic, S., \& Siemens, G. (2014). Where is research on massive open online courses headed? A data analysis of the MOOC Research Initiative. The International Review of Research in Open and Distributed Learning, 15(5), 134-176. Retrieved from http://www.irrodl.org/index.php/irrodl/article/view/1954/3099

Glance, D. G., Forsey, M., \& Riley, M. (2013). The pedagogical foundations of massive open online courses. First Monday, 18(5). http://dx.doi.org/10.5210/fm.v18i5.4350

Greenhalgh, T., \& Peacock, R. (2005). Effectiveness and efficiency of search methods in systematic reviews of complex evidence: Audit of primary sources. British Medical Journal, 331(7524), 10641065. http://dx.doi.org/10.1136/bmj.38636.593461.68

Hood, N., Littlejohn, A., \& Milligan, C. (2015). Context counts: How learners’ contexts influence learning in a MOOC. Computers \& Education, 91, 83-91. http://dx.doi.org/10.1016/j.compedu.2015.10.019

Johnson, L., Becker, S., Estrada, V. \& Freeman, A. (2014). NMC Horizon report: 2014 Higher Education Edition. Austin, TX: New Media Consortium.

Jo, Y., Tomar, G., Ferschke, O., Rose, C. P., \& Gasevic, D. (2016). Expediting support for social learning with behavior modeling. arXiv preprint arXiv:1605.02836. Retrieved from https://arxiv.org/pdf/1605.02836.pdf

Kitsantas, A., \& Dabbagh, N. (2011). The role of Web 2.0 technologies in self-regulated learning. New Directions for Teaching and Learning, 2011(126), 99-106. http://dx.doi.org/10.1002/tl.448

Kizilcec, R. F., \& Halawa, S. (2015, March). Attrition and achievement gaps in online learning. Paper presented at Learning@Scale 2015, Vancouver. http://dx.doi.org/10.1145/2724660.2724680

Kizilcec, R. F., Pérez-Sanagustín, M., \& Maldonado, J. J. (2016, April). Recommending self-regulated learning strategies does not improve performance in a MOOC. Paper presented at Learning@Scale 2016, Edinburgh. http://dx.doi.org/10.1145/2876034.2893378 
Kizilcec, R. F., Pérez-Sanagustín, M., \& Maldonado, J. J. (2017). Self-regulated learning strategies predict learner behavior and goal attainment in Massive Open Online Courses. Computers \& Education, 104, 18-33. http://dx.doi.org/10.1016/j.compedu.2016.10.001

Lee, Y., Choi, J., \& Kim, T. (2012). Discriminating factors between completers of and dropouts from online learning courses. British Journal of Educational Technology, 44(2), 328-337. http://dx.doi.org/10.1111/j.1467-8535.2012.01306.x

Liang-Yi, C. (2015). Exploring the effectiveness of self-regulated learning in Massive Open Online Courses on non-native English speakers. International Journal of Distance Education Technologies, 13(3), 61-73. http://dx.doi.org/10.4018/IJDET.2015070105

Littlejohn, A., Hood, N., Milligan, C., \& Mustain, P. (2016). Learning in MOOCs: Motivations and selfregulated learning in MOOCs. The Internet and Higher Education, 29, 40-48. http://dx.doi.org/10.1016/j.iheduc.2015.12.003

Littlejohn, A., \& Milligan, C. (2015). Designing MOOCs for professional learners: Tools and patterns to encourage self-regulated learning. eLearning Papers, 42, 38-45. Retrieved from http://oro.open.ac.uk/46385/3/Design_Patterns_for_Open_Online_Teaching_and_Learning_Design_P aper_42_4.pdf

Magen-Nagar, N., \& Cohen, L. (2016). Learning strategies as a mediator for motivation and a sense of achievement among students who study in MOOCs. Education and Information Technologies, 1-20. http://dx.doi.org/10.1007/s10639-016-9492-y

Margaryan, A., Littlejohn, A., \& Milligan, C. (2013). Self-regulated learning in the workplace: Learning goal attainment strategies and factors. International Journal of Training and Development, 17(4), 254-259. http://dx.doi.org/10.1111/ijtd.12013

Milligan, C., \& Littlejohn, A. (2016). How health professionals regulate their learning in massive open online courses. The Internet and Higher Education, 31, 113-121. http://dx.doi.org/10.1016/j.iheduc.2016.07.005

Milligan, S. K., \& Griffin, P. (2016). Understanding learning and learning design in MOOCs: A measurement-based interpretation. Journal of Learning Analytics, 3(2), 88-115. http://dx.doi.org/10.18608/jla.2016.32.5

Morales Chan, M., Hernandez Rizzardini, R., Barchino Plata, R., \& Amelio Medina, J. (2015). MOOC using cloud-based tools: A study of motivation and learning strategies in Latin America. International Journal of Engineering Education, 31(3), 901-911. Retrieved from http://www.ijee.ie/latestissues/Vol31-3/22_ijee3046ns.pdf

Nawrot, I., \& Doucet, A. (2014, April). Building engagement for MOOC students: Introducing support for time management on online learning platforms. Paper presented at the 23rd International World Wide Web Conference, Seoul, South Korea. http://dx.doi.org/10.1145/2567948.2580054

Onah, D. F. O, \& Sinclair, J. E. (2016, September). A multi-dimensional investigation of self-regulated learning in a blended classroom context: A case study on eLDa MOOC. In M. E. Auer, G. Guralnick, \& J. Uhomoibhi (Eds.), Proceedings of the 19th International Conference on Interactive Collaborative Learning (pp. 63-85). Springer. http://dx.doi.prg/10.1007/978-3-319-50340-0

Park, T. J., Cha, H. J., \& Lee, G.Y. (2016). A study on design guidelines of learning analytics to facilitate self-regulated learning in MOOCs. Educational Technology International, 17(1), 117-150. Retrieved from http://kset.or.kr/eti_ojs/index.php/instruction/article/viewFile/61/pdf_19

Perna, L. W., Ruby, A., Boruch, R. F., Wang, N., Scull, J., Ahmad, S., \& Evans, C. (2014). Moving through MOOCs: Understanding the progression of users in massive open online courses. Educational Researcher, 43(9), 421-432. https://doi.org/10.3102/0013189X14562423

Petticrew, M., \& Roberts, H. (2008). Systematic reviews in the social sciences: A practical guide. Malden, MA: Blackwell.

Pintrich, P. R. (1999). The role of motivation in promoting and sustaining self-regulated learning. International Journal of Educational Research, 31(6), 459-470. http://dx.doi.org/10.1016/S08830355(99)00015-4

Pintrich, P. R. (2000). The role of goal orientation in self-regulated learning, In M. Boekaerts, P.R. Pintrich, \& M Zeidner (Eds.), Handbook of self-regulation (pp. 451-502). San Diego, CA: Academic.

Pintrich, P. R., Smith, D. A. F., Garcia, T., \& McKeachie, W. J. (1991). A manual for the use of the Motivated Strategies for Learning Questionnaire (MSLQ). Ann Arbor: The University of Michigan.

Schunk, D. H. (1989). Social cognitive theory and self-regulated learning. In B. J. Zimmerman \& D. H. Schunk (Eds.), Self-regulated learning and academic achievement: Theory, research, and practice (pp. 83-110). New York, NY: Springer Verlag. 
Rowe, F. A., \& Rafferty, J. A. (2013). Instructional design interventions for supporting self-regulated learning: enhancing academic outcomes in postsecondary e-learning environments. Journal of Online Learning and Teaching, 9(4), 590-601. Retrieved from http://jolt.merlot.org/vol9no4/rowe_1213.pdf

Terras, M. M., \& Ramsay, J. (2015). Massive open online courses (MOOCs): Insights and challenges from a psychological perspective. British Journal of Educational Technology, 46(3), 472-487. http://dx.doi.org/10.1111/bjet.12274

Tschofen, C., \& Mackness, J. (2012). Connectivism and dimensions of individual experience. The International Review of Research in Open and Distributed Learning, 13(1), 124-143. http://dx.doi.org/10.19173/irrodl.v13i1.1143

Zimmerman, B. J. (2000a). Attaining self-regulation: A social cognitive perspective. In M. Boekaerts, P. Pintrich, \& M. Zeidner (Eds.), Handbook of self-regulation (pp. 13-39). San Diego, CA: Academic Press.

Zimmerman, B. J. (2000b). Self-efficacy: An essential motive to learn. Contemporary Educational Psychology, 25(1), 82-91. http://dx.doi.org/10.1006/ceps.1999.1016

Zimmerman, B. J., \& Pons, M. M. (1986). Development of a structured interview for assessing student use of self-regulated learning strategies. American Educational Research Journal, 23(4), 614-628. http://dx.doi.org/10.3102/00028312023004614

Corresponding author: Daeyeoul Lee, lee1895@purdue.edu

Australasian Journal of Educational Technology (C) 2019.

Please cite as: Lee, D., Lee, S. L., \& Watson, W. R. (2019). Systematic literature review on selfregulated learning in massive open online courses. Australasian Journal of Educational Technology, 35(1), 28-41. https://doi.org/10.14742/ajet.3749 